\title{
BREWER'S SPENT GRAIN AND CORN STEEP LIQUOR AS ALTERNATIVE CULTURE MEDIUM SUBSTRATES FOR PROTEINASE PRODUCTION BY STREPTOMYCES MALAYSIENSIS AMT-3
}

\author{
Rodrigo Pires do Nascimento ${ }^{1 *}$, Nelson Alves Junior ${ }^{2}$, Rosalie Reed Rodrigues Coelho ${ }^{2}$ \\ ${ }^{1}$ Centro de Ciências Agrárias, Ambientais e Biológicas, Universidade Federal do Recôncavo da Bahia, Cruz das Almas, BA, \\ Brasil; ${ }^{2}$ Instituto de Microbiologia Prof. Paulo de Góes, Universidade Federal do Rio de Janeiro, Rio de Janeiro, RJ, Brasil.
}

Submitted: September 18, 2010; Returned to authors for corrections: February 08, 2011; Approved: June 06, 2011.

\begin{abstract}
Brewer's spent grain and corn steep liquor or yeast extract were used as the sole organic forms for proteinase production by Streptomyces malaysiensis in submerged fermentation. The influence of the $\mathrm{C}$ and $\mathrm{N}$ concentrations, as well as the incubation periods, were assessed. Eight proteolytic bands were detected through gelatin-gel-electrophoresis in the various extracts obtained from the different media and after different incubation periods, with apparent molecular masses of 20, 35, 43, 50, 70, 100, 116 and $212 \mathrm{kDa}$. The results obtained suggest an opportunity for exploring this alternative strategy for proteinases production by actinomycetes, using BSG and CSL as economically feasible substrates.
\end{abstract}

Key words: Streptomyces malaysiensis; brewer's spent grains; corn steep liquor; proteinases; submerged fermentation.

Proteinases are industrially important enzymes, which catalyze the hydrolysis of a peptide bond in a protein molecule, and they are used in various industries such as the detergent, leather, textile, pharmaceutical industry and for waste treatment. Microbial proteinases, especially from Bacillus sp., have traditionally held a predominant share of the industrial enzyme market worldwide (1). Several extracellular proteinases have been obtained from streptomycetes (2) and many of them have been characterized as serine- and metalloproteinases $(3,4,5)$

Brewer's spent grain (BSG) is a by-product of the brewery industry, and is the barley malt residue obtained after wort elaboration, with a cellulose content ranging from $9 \%$ to $25 \%$ of the dry matter (6). According to Mussato et al. (7), breweries in Brazil generate approximately 1.9 millions tons of BSG per year. Although part of it is used as animal feed, it is still largely underused. However it is an interesting source as the raw material for the production of a variety of products including lactic acid (7) and breads (8). Recently it has been used for enzyme production, such as arabinoxylan-degrading enzymes (9), and also cellulases and hemicellulases for bioethanol production (7).

Corn steep liquor (CSL), a major by-product of the corn wet-milling industry, is also an inexpensive substrate available on a large scale (10), and is capable of replacing yeast extract (YE) as a rich source of nutrients such as organic nitrogen and 
vitamins. This cheap residue has been successfully used in some culture media for the production of glucose isomerase (11), cellulase (12) and protease (13).

This present report deals with the production of proteinases by Streptomyces malaysiensis AMT-3 isolated from a Brazilian cerrado soil (14), using BSG as the carbon source, and CSL or YE as the nitrogen source. Stock cultures were maintained on yeast extract-malt extract-agar plates containing (g/L): malt extract, 10; yeast extract, 4; glucose, 4 and agar, 15 , after incubation at $28^{\circ} \mathrm{C}$ for 10 days. For spore production the streptomycete was cultivated for 15 days in this same medium and spore suspension, prepared according to Hopwood et al. (15), was maintained in $20 \%(\mathrm{v} / \mathrm{v})$ glycerol at $20^{\circ} \mathrm{C}$.

Cells were cultivated in a salt mineral medium containing $\left(\mathrm{g} \mathrm{L}^{-1}\right): \mathrm{KH}_{2} \mathrm{PO}_{4}, 9.0 ; \mathrm{K}_{2} \mathrm{HPO}_{4}, 1.5 ; \mathrm{MgSO}_{4} .7 \mathrm{H}_{2} \mathrm{O}, 0.2 ; \mathrm{CaCl}_{2}$, 0.05; $\mathrm{MnSO}_{4} .7 \mathrm{H}_{2} \mathrm{O}, \quad 0.01$ and $\mathrm{ZnSO}_{4} .7 \mathrm{H}_{2} \mathrm{O}, \quad 0.001$, supplemented with different combinations of BSG as the carbon source, and CSL or YE as the nitrogen source. The different combinations that generated the eight (8) culture mediums were as follows: [1] YE 0.1\% (w/v) and BSG 0.5\% (w/v); [2] YE 0.1\% (w/v) and BSG 2.5\% (w/v); [3] YE 1.2\% (w/v) and BSG 0.5\% (w/v); [4] YE 1.2\% (w/v) and BSG 2.5\% (w/v); [5] CSL 0.1\% (w/v) and BSG 0.5\% (w/v); [6] CSL 0.1\% $(\mathrm{w} / \mathrm{v})$ and BSG 2.5\% (w/v); [7] CSL 1.2\% (w/v) and BSG $0.5 \%(\mathrm{w} / \mathrm{v})$; [8] CSL $1.2 \%(\mathrm{w} / \mathrm{v})$ and BSG 2.5\% (w/v). Erlenmeyer flasks $(250-\mathrm{mL})$, containing $50 \mathrm{~mL}$ of each medium, were inoculated with $50 \mu \mathrm{L}$ of a spore suspension $(4.4$ x $10^{9}$ spores $/ \mathrm{mL}$ ). Cells were incubated at $28^{\circ} \mathrm{C}$, under shaking conditions (200 rpm) for 6 days. At 24 hour intervals flasks were collected, in duplicates, and the contents were centrifuged for $10 \mathrm{~min}(2,500 \mathrm{~g})$ at $4^{\circ} \mathrm{C}$, after which the supernatants, which were passed through a $0.45 \mu \mathrm{m}$ filtration unit, were collected for further analysis.

The extracellular proteinase activity was detected by $10 \%$ sodium dodecylsulfate-polyacrylamide gel electrophoresis (SDS-PAGE) containing $0.1 \%$ gelatin (16). The crude extracts were mixed with SDS-PAGE sample buffer (4) in a proportion of 7:3 (extract:buffer - v/v). After electrophoresis $(200 \mathrm{mV}, 4$ hours, $4^{\circ} \mathrm{C}$ ) the gel strips were submerged in Triton X-100 for 30 minutes in an ice bath and than incubated in $50 \mathrm{mM}$ phosphate buffer, $\mathrm{pH} 7.0$, for $4 \mathrm{~h}$ at $37^{\circ} \mathrm{C}$. The possible presence of protein aggregates was evaluated by preparing the extracts in two different ways: (a) a non-reduced sample was mixed with SDS-PAGE buffer and (b) a reduced sample was prepared by boiling for $5 \mathrm{~min}$ in SDS-PAGE buffer containing $2 \mathrm{mM}$ DTT (dithiothreitol). Thereafter, the extracts were analyzed in SDS-PAGE in the presence or absence of gelatin. The molecular mass of the proteinases was calculated by comparison against the mobility of the molecular mass standards (Pharmacia): myosin (212 kDa), $\alpha-2$ macroglobulin (170 kDa), $\beta$-galactosidase (116 kDa), phosphorylase b (97 $\mathrm{kDa})$, albumin (66 kDa), ovalbumin (45 kDa), carbonic anhydrase $(30 \mathrm{kDa})$, trypsin inhibitor $(20.1 \mathrm{kDa})$ and $\beta$ lactalbumin $(14.4 \mathrm{kDa})$.

Eight proteolytic bands were detected in the various extracts obtained from the different media and after different incubation periods (Fig 1 and 2). The results were the same for the duplicates tested. These bands correspond to molecular masses of 20, 35, 43, 50, 70, 100, 116 and $212 \mathrm{kDa}$, and band $116 \mathrm{kDa}$, present in all conditions tested, was the most characteristic one. The possible presence of protein aggregates was eliminated, since the same protein profile was obtained after the extracts, boiled in SDS and DTT, were analyzed in SDS-PAGE in the presence or absence of gelatin (data not shown).

In terms of the BSG concentration, or even the type of nitrogen source, CSL or YE, the results obtained were variable, and a common proteolytic profile could not be established. So, in general, the combination of BSG at 0.5 or $2.5 \%(\mathrm{w} / \mathrm{v})$ with CSL or YE, at 0.1 or $1.2 \%(\mathrm{w} / \mathrm{v})$ was adequate for proteinase production. Extracellular proteinase production in microorganisms is highly influenced by media components, viz. a variation in $\mathrm{C} / \mathrm{N}$ ratio, the presence of some easily 
metabolizable sugars, such as glucose, and the presence of metal ions $(2,17,18,19)$. Due to these factors, a large heterogeneity can be observed in the proteinase production in response to the type and concentration of the substrates in the culture medium, which could explain the variability of the results obtained.
A

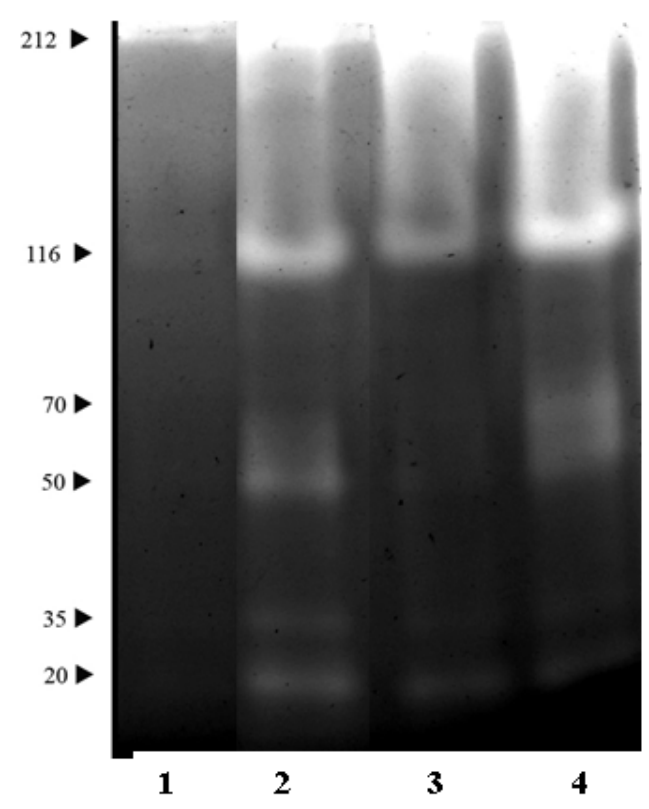

C

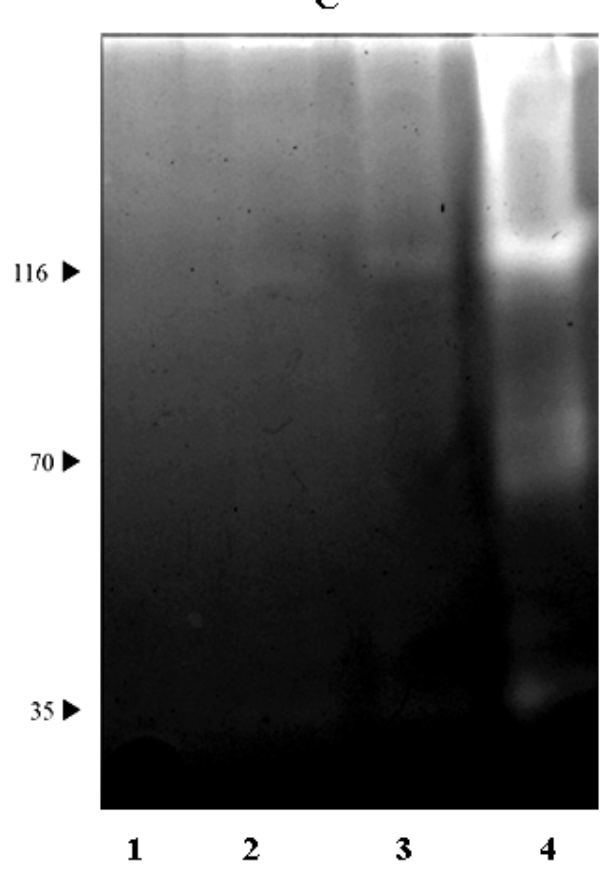

$\mathbf{B}$
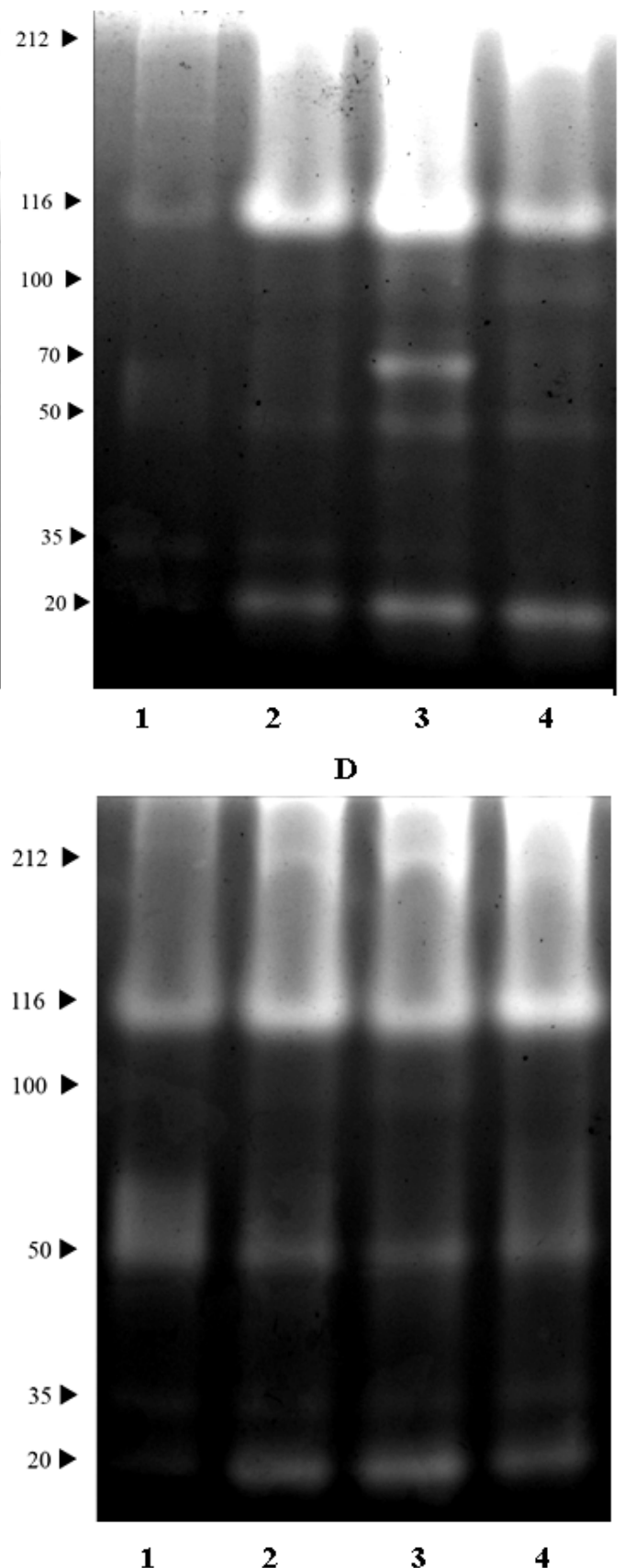

Figure 1. Gelatin-SDS-PAGE showing proteinases in the culture supernatant of $S$. malaysiensis grown under different concentrations of BSG and CSL, for a period ranging from 3 to 6 days. (A) BSG $0.5 \%+$ CSL $0.1 \%$, (B) BSG $2.5 \%+$ CSL $0.1 \%$, (C) BSG $0.5 \%+$ CSL $1.2 \%$ and (D) BSG 2.5\% + CSL 1.2\%. Lanes 1-4 correspond to the different days (3-6 days). The calculated molecular masses (in kDa) of the proteinases are indicated on the left side of the Figure. 
A
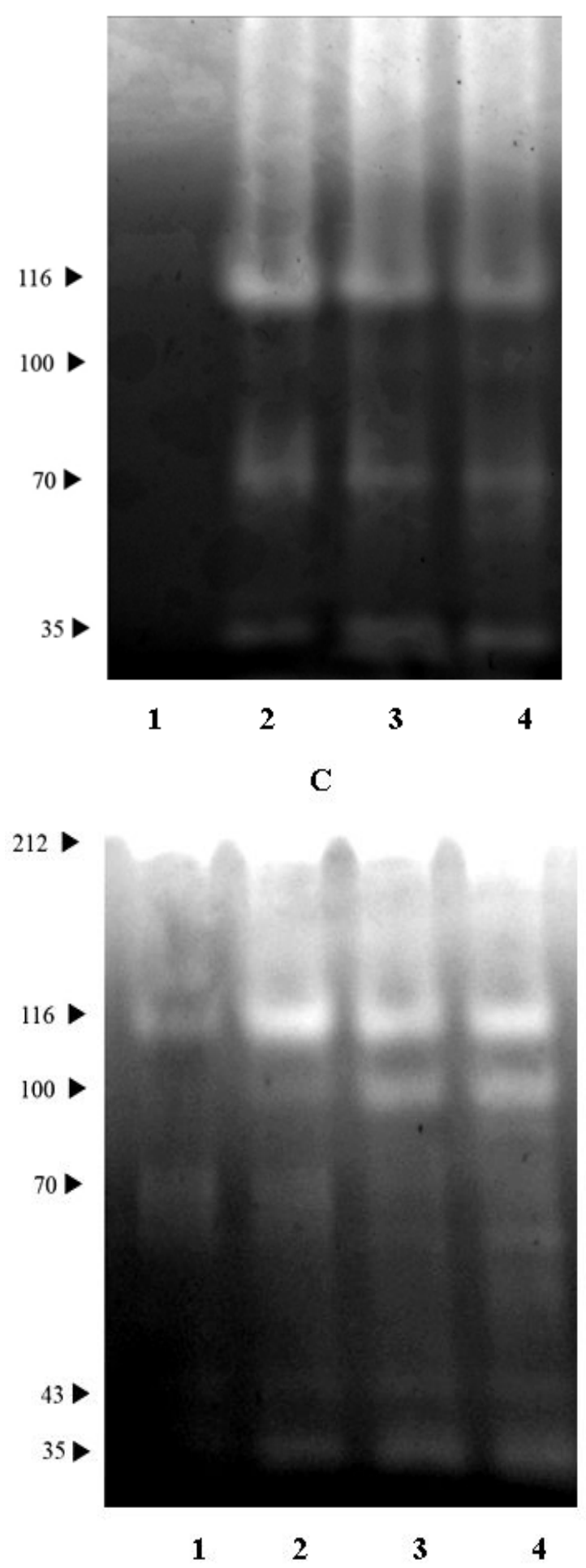

B
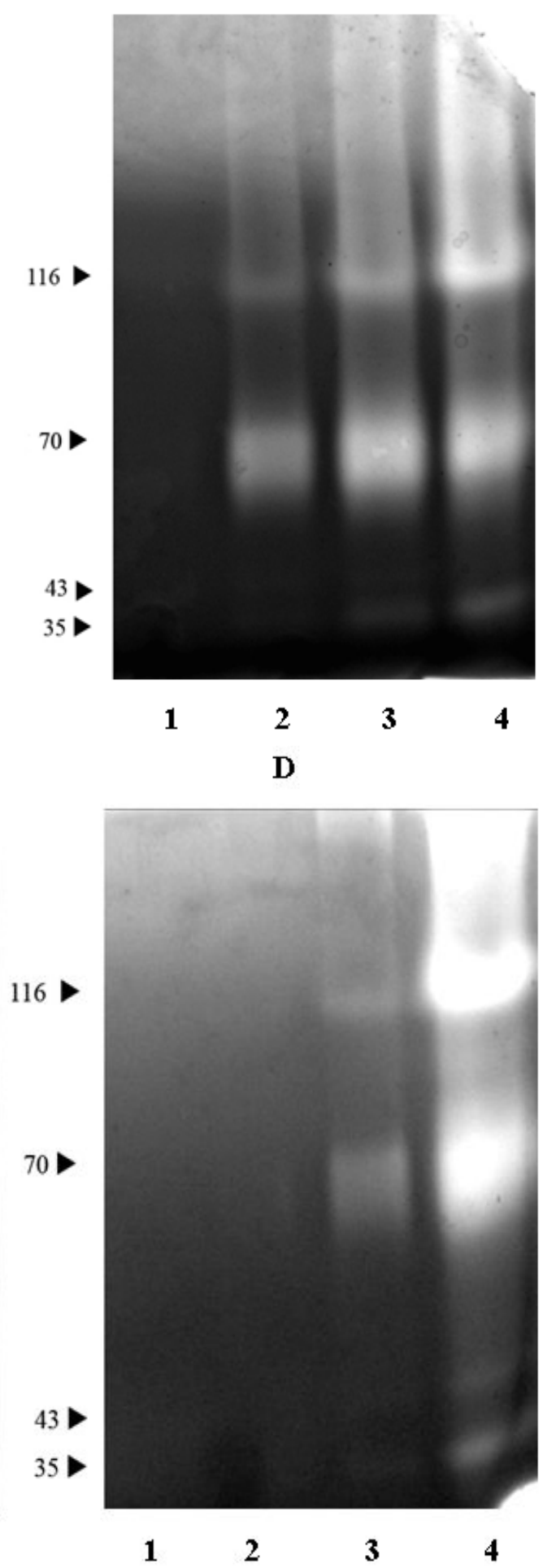

Figure 2. Gelatin-SDS-PAGE showing proteinases in the culture supernatant of $S$. malaysiensis grown under different concentrations of BSG and YE, for a period ranging from 3 to 6 days. (A) BSG $0.5 \%+$ YE $0.1 \%$, (B) BSG 2.5\% + YE 0.1\%, (C) BSG 0.5\% + YE 1.2\% and (D) BSG $2.5 \%+$ YE 1.2\%. Lanes 1-4 correspond to the different days (3-6 days). The calculated molecular masses (in kDa) of the proteinases are indicated on the left side of the Figure. 
The proteolytic bands were generally more intense after 4-6 days fermentation, however, occasionally, even after 3 days they could be detected, as observed, for instance, when $2.5 \%(\mathrm{w} / \mathrm{v})$ BSG and $1.2 \%$ (Fig. 1D) or $0.1 \%(\mathrm{w} / \mathrm{v})$ CSL (Fig. 1B) were used. However, under other conditions, such as when $0.5 \%(\mathrm{w} / \mathrm{v}) \mathrm{BSG}$ and $1.2 \%(\mathrm{w} / \mathrm{v})$ CSL (FIG $1 \mathrm{C}$ ), or when $2.5 \%$ $(\mathrm{w} / \mathrm{v})$ BSG and 1.2\% (w/v) YE (Fig 2D) were employed, the proteolytic profile was detected only after five days, and was only more intense after six days incubation.

Streptomyces malaysiensis was tested previously for proteinase production using wheat bran (WB) and YE (4) and the same eight proteolytic bands were detected. They were characterized as serine-proteinases $(212,116,100$, and $35 \mathrm{kDa})$ and metallo-proteinases $(20,43,50$ and $70 \mathrm{kDa})$ classes. Our results indicate that the proteolytic enzymes obtained here are the same as those observed earlier, although the quantification of proteinases seemed to be different. Indeed this is a very interesting result, which indicates that for a possible future biotechnological application, different low cost residues, such as BSG and WB, could be used for the production of the same proteinases. Considering that BSG is readily available, and considering also the differences in costs of both CSL and YE, it is evident that these results are of significant importance, which points out the possibility of using BSG and CSL as sole sources of $\mathrm{C}$ and $\mathrm{N}$ for proteinase production. According to the literature BSG is not a very commonly used substrate, and at the present time, as far as we know, there are no citations describing proteinase production using only these two residues.

In conclusion, $S$. malaysiensis AMT-3, a strain isolated from a Brazilian cerrado soil, was able to grow and produce proteinases using BSG and CSL, which are low-cost substrates and are therefore very interesting for enhancing the potential use of this proteolytic strain in biotechnological applications.

\section{ACKNOWLEDGEMENTS}

This work was supported by Conselho Nacional de Desenvolvimento Científico e Tecnológico (MCT/CNPq)
Grant 201080/2004-4, Coordenação de Aperfeiçoamento de Pessoal do Ensino Superior (CAPES) and Conselho de Ensino para Graduados e Pesquisas (CEPG/UFRJ).

\section{REFERENCES}

1. Beg, Q.K.; Sahai, V.; Gupta, R. (2003). Statistical media optimization and alkaline protease production from Bacillus mojavensis in a bioreactor. Proc Biochem, 39, 203-209.

2. Chen, W.P.; Anderson, A.W.; Han, Y.W. (1979). Production of glucose isomerase by Streptomyces flavogriseus. Appl Environ Microbiol 37, 324-331.

3. De Azeredo, L.A.I.; De Lima, M.B.; Coelho, R.R.R.; Freire, D.M.G. (2006). A low-cost fermentation medium for thermophilic protease production by Streptomyces sp 594 using feather meal and corn steep liquor. Curr Microbiol, 53, 335-339.

4. De Azeredo, L.A.I.; Freire, D.M.G.; Soares, R.M.A.; Leite, S.G.L.; Coelho. R.R.R. (2004). Production and partial characterization of thermophilic proteases from Streptomyces sp. isolated from Brazilian cerrado soil. Enz. Microb Technol, 34, 354-358.

5. Ferrero, M.A.; Cartro, G.R.; Abate, C.M.; Baigori, M.D.; Sineriz, F. (1996). Thermostable alkaline protease of Bacillus licheniformis MIR 29: isolation, production and characterization. Appl Microbiol Biotechnol, 45, 327-332.

6. Grigorevski-Lima, A.L.; Nascimento, R.P.; Bon, E.P.S.; Coelho, R.R.R. (2005). Streptomyces drozdowiczii cellulase production using agroindustrial by-products and its potential use in the detergent and textile industries. Enz. Microb. Technol., 37, 272-277.

7. Gupta, R.; Beg, Q.K.; Khan, S.; Chauhan, B. (2002). An overview on fermentation, downstream processing and properties of microbial alkaline protease. Appl Microbiol Biotechnol, 60, 381-395.

8. Hopwood, D.A.; Bibb, M.J.; Chater, K.F.; Kieser, T.; Bruton, C.J. (1985). Genetic manipulation of Streptomyces. In: A laboratory Manual. The John Innes Institute, Norwich, United Kingdom.

9. Melo, A.C.N.; D’Avila-Levy, C.M.; Branquinha, M.H.; Vermelho, A.B. (2002). Crithidia guilhermei: gelatin- and haemoglobin-degrading extracellular metalloproteinases. Exp. Parasitol., 102, 150-156.

10. Moreira, K.A.; Porto, T.S.; Teixeira, M.F.S.; Porto, A.L.F.; Lima Filho, J.L. (2003). New alkaline protease from Nocardiopsis sp.: partial purification and characterization. Process Biochem, 39, 67-72

11. Mussatto, S.I.; Fernandes, M.; Mancilha, I.M.; Roberto, I.C. (2008). Effects of medium supplementation and $\mathrm{pH}$ control on lactic acid production from brewer's spent grain. Biochem Eng J, 40, 437-444.

12. Nascimento, R.P.; D’Ávila-Levy, C.M.; Souza, R.F.; Branquinha, M.H.; Bon, E.P.S.; Coelho, R.R.R. (2005). Production and partial 
characterization of extracellular proteinases from Streptomyces malaysiensis AMT-3 isolated from a Brazilian cerrado soil. Arch Microbiol, 184, 194-198.

13. Nascimento, R.P.; Marques, S.; Alves, L.; Gírio, F.M.; Amaral-Collaço, M.T.; Coelho, R.R.R. (2003). A novel strain of Streptomyces malaysiensis isolated from Brazilian soil produces high endo- $\beta-1,4-$ xylanase titres. World J Microbiol Biotechnol 19, 879-881.

14. Panagiotou, G.; Granouillet, P.; Olsson, L. (2006). Production and partial characterization of arabinoxylan-degrading enzymes by Penicillium brasilianum under solid-state fermentation. Appl Microbiol Biotechnol 72,1117-1124.

15. Parekh, M.; Formanek, J.; Blaschek, H.P. (1999). Pilot-scale production of butanol by Clostridium beijerinckii BA101 using a low-cost fermentation medium based on corn steep water. Appl Microbiol Biotechnol 51,152-157.
16. Petinate, S.D.G.; Branquinha, M.H.; Coelho, R.R.R.; Vermelho, A.B.; Giovanni de Simone, S. (1999). Purification and partial characterization of an extracellular serine-proteinase of Streptomyces cyaneus isolated from Brazilian cerrado soil. J Appl Microbiol 87, 557-563.

17. Stojceska, V.; Ainsworth, P. (2008). The effect of different enzymes on the quality of high-fibre enriched brewer's spent grain breads. Food Chem 110, 865-872.

18. Varela, H.; Ferrari, M.D.; Belobradjic, L.; Weyrauch, R.; Loperena, M.L. (1996). Effect of medium composition on the production by a new Bacillus subtilis isolate of protease with promising unhearing activity. World J Microbiol Biotechnol 12, 643-645.

19. Xiros, C.; Topakas, E.; Katapodis, P.; Christakopoulos, P. (2008). Evaluation of Fusarium oxysporum as an enzyme factory for the hydrolysis of brewer's spent grain with improved biodegradability for ethanol production. Ind Crops Prod 28, 213-224. 